\title{
Social and behavior change programming landscape for out-of- school adolescent and youth reproductive health programs in the Philippines: A scoping review
}

Breakthrough RESEARCH

Follow this and additional works at: https://knowledgecommons.popcouncil.org/departments_sbsr-rh How does access to this work benefit you? Let us know!

\section{Recommended Citation}

Breakthrough RESEARCH. 2020. "Social and behavior change programming landscape for out-of-school adolescent and youth reproductive health programs in the Philippines: A scoping review," Programmatic Research Brief. Washington, DC: Population Council. 


\section{Social and Behavior Change Programming Landscape for Out-of-School Adolescent and Youth Reproductive Health Programs in the Philippines: A scoping review}

Adolescent and youth reproductive health (AYRH) is a considerable concern in the Philippines, particularly as the country's adolescent population increases. With this increase comes greater concern for young people's engagement in risky behaviors and rising rates of child bearing among 15 - to 19 -year-olds. Filipino youth also have limited knowledge and sources of information about reproductive health $(\mathrm{RH})$ and family planning (FP). Risky sexual behaviors are amplified for out-of-school youth (OSY) who not only engage in riskier behaviors but who also are left out-of-school-based programming for young people. Although there have been many efforts to address issues and behaviors related to ARYH in the Philippines, a synthesized understanding of the programming landscape, particularly as it pertains to social and behavior change (SBC) interventions that aim to improve RH and FP behaviors of Filipino OSY, remains limited. The state of knowledge on current SBC interventions, the themes and approaches applied, and their impact on improving key OSY FP/RH behaviors and outcomes remains fragmented. This knowledge gap can lead to inefficiencies in programming due to lack of coordination, duplication of effort, and most importantly, prevention of effective design of future interventions to address important $\mathrm{RH}$ and FP issues of Filipino OSY.

This research brief presents key findings of a scoping review of past and present SBC programs targeting male and female OSY aged 15 to 19 in the Philippines, with particular focus on four priority $\mathrm{RH}$ behaviors:

1. Delay of sexual debut

2. Use of modern contraceptive methods to prevent teen pregnancy

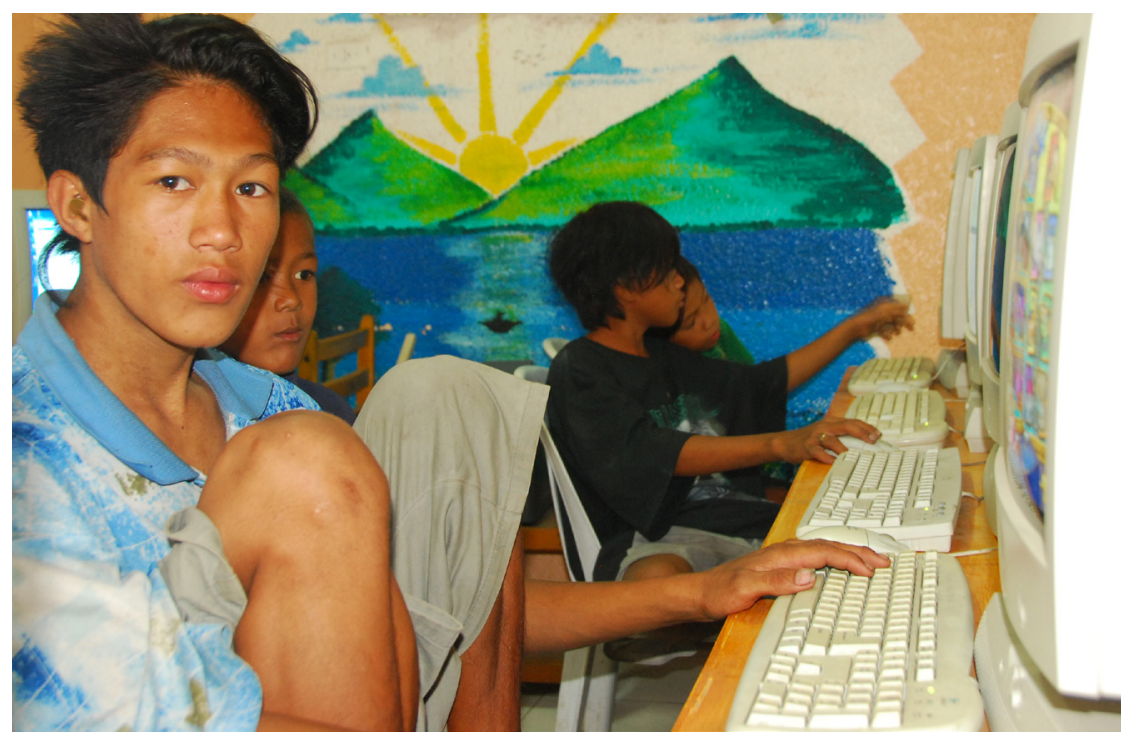

JON MANNION (CC BY-NC-ND 2.0)
3. Care-seeking in first trimester of pregnancy

4. Birth spacing of three to five years to prevent short birth intervals

This scoping review is part of a broader research study carried out by the Population Council's Breakthrough RESEARCH Project with financial support from the United States Agency for International Development (USAID)/ Philippines. It aims to generate evidence to create SBC approaches that are effective in reaching male and female OSY aged 15 to 19 in the Philippines around priority FP and RH behaviors. In particular, the overall objective for this scoping review is to facilitate a deeper understanding of the SBC programming landscape in the Philippines with the following specific objectives:

- Assess to what extent OSY and adolescents aged 15 to 19 have been targeted as a primary beneficiary group among SBC programs in the Philippines; 
- Assess to what extent the four priority FP/RH behaviors have been targeted by past and present SBC programs for OSY and adolescents aged 15 to 19 in the Philippines;

- Identify strategies employed by past and present SBC programs to promote positive behavior change among Filipino OSY and adolescents aged 15 to 19; and

- Examine the state of evidence regarding effectiveness of past and present programs in promoting positive behavior changes among OSY and adolescents aged 15 to 19 in the Philippines.

\section{METHODS}

\section{Inclusion criteria}

SBC programs in the Philippines were included in this review if they met the following criteria:

- Included adolescents and youth as a target beneficiary (adolescents aged 15 to 19 were the segment of primary interest; however, any program that addressed youth aged 10 to 24 was included),

- Focused on bringing positive behavior change to Filipino adolescents and youth, with particular focus on FP and $\mathrm{RH}$, and

- Were implemented in the Philippines during the last five years (2013-2018).

\section{BOX 1 PROGRAMS TARGETING OSY AND ADOLESCENTS AGED 15 TO 19}

OSY: Four programs

Adolescents aged 15 to 19: Six programs

OSY aged 15 to 19: One program

\section{Sources of information}

Detailed information about SBC programs was collected from three main sources:

- Documents produced by programs: Project documents consulted include project reports, briefs or summaries, fact sheets, newsletters, baseline reports, and endline reports.
- Online resources: In addition to project documents, the information search included relevant nongovernmental organizations (NGOs), multilateral and bilateral organizations and donors, and government websites and Google searches for additional project information.

- Scoping visit: A number of stakeholders from various programs and organizations in the Philippines were consulted during an in-person scoping visit conducted in Manila in 2018 to ensure the review included all relevant programs (see Annex 1 for list of programs and organization consulted).

\section{PROGRAMS INCLUDED}

Fifteen programs/projects that fulfilled the three inclusion criteria were identified (see Table 1 for list of programs that were reviewed). Approximately two-thirds of those programs were still operational without a predetermined completion date, while four programs will last, with varying end dates, until 2023. A majority of the programs received funding from a single source, while six programs had multiple donors. The United Nations Population Fund (UNFPA), United Nations Children's Fund (UNICEF), and USAID were the three major funders in terms of number of programs funded (no information about budget sizes was available). The Filipino government was the lead implementer of half of the reviewed programs and co-led several others.

\section{RESULTS}

This review analyzed the fifteen identified programs based on four aspects: the extent the programs have targeted OSY and adolescents aged 15 to 19 years old; thematic focus areas of the programs, with particular focus on the four priority RH behaviors identified above; SBC approaches employed by the programs; and program evaluation, specifically regarding the rigor of the assessments of how effective the employed SBC approaches were in promoting positive behavior change among the target groups of the programs, including OSY and adolescents aged 15 to 19 years old.

\section{Inclusion of OSY and adolescents aged 15 to 19 years old}

Among the fifteen identified programs, four programs (ALS, STEP, ADAPP, and MYDev) targeted OSY as their main beneficiaries. Ten programs focused on adolescents, 
TABLE 1 ABBREVIATIONS OF REVIEWED PROGRAMS AND ABBREVIATIONS

\begin{tabular}{|c|c|c|c|c|c|}
\hline No. & Project/Program & Implementer & Location & Funder & $\begin{array}{l}\text { Project } \\
\text { Timeframe }\end{array}$ \\
\hline 1 & $\begin{array}{l}\text { Primary Health Care Services and } \\
\text { Counselling for Women }\end{array}$ & Likhaan & Metro Manila & $\begin{array}{l}\text { Multiple donors } \\
\text { including UNFPA and } \\
\text { UNICEF }\end{array}$ & 1995-present \\
\hline 2 & $\begin{array}{l}\text { Community Organizing and } \\
\text { Education }\end{array}$ & Likhaan & Central Philippines & $\begin{array}{l}\text { Multiple donors } \\
\text { including UNFPA and } \\
\text { UNICEF }\end{array}$ & 1995-present \\
\hline 3 & Adolescent and Youth Program & $\begin{array}{l}\text { UNFPA, National } \\
\text { Government Agencies } \\
\text { and NGOs }\end{array}$ & $\begin{array}{l}\text { Mindanao and at } \\
\text { the national level }\end{array}$ & UNFPA & 2019-2023 \\
\hline 4 & $\begin{array}{l}\text { AHDP (Adolescent Health and } \\
\text { Development Program) }\end{array}$ & $\begin{array}{l}\text { Philippines Department } \\
\text { of Health (DoH) }\end{array}$ & Nationwide & UNICEF & 2018-2022 \\
\hline 6 & $\begin{array}{l}\text { SUGPAT Adolescent Development } \\
\text { and Participation Program (ADAPP) }\end{array}$ & $\begin{array}{l}\text { Ateneo de Zamboanga } \\
\text { University's Center for } \\
\text { Culture and the Arts } \\
\text { (with Department of } \\
\text { Education) }\end{array}$ & Zamboanga City & UNICEF & 2018-present \\
\hline 7 & Youth Program & Roots of Health (RoH) & Palawan Province & Multiple donors & 2017-present \\
\hline 8 & Healthy Pregnancy Program & Roots of Health $(\mathrm{RoH})$ & Palawan Province & Multiple donors & 2017-present \\
\hline 9 & You-for-You (U4U) & $\begin{array}{l}\text { Philippines Commission } \\
\text { on Population } \\
\text { (POPCOM) and the } \\
\text { Center for Health } \\
\text { Solutions and } \\
\text { Innovation (CHSI) }\end{array}$ & $\begin{array}{l}\text { Online-based and } \\
\text { school/community- } \\
\text { based reaching } 60 \\
\text { provinces and cities }\end{array}$ & UNFPA & 2014-present \\
\hline 11 & $\begin{array}{l}\text { Integrated Maternal, Neonatal, } \\
\text { Child Health, and Nutrition/Family } \\
\text { Planning Regional Project in Luzon } \\
\text { (LuzonHealth) }\end{array}$ & $\begin{array}{l}\text { RTI International and } \\
\text { Jhpiego }\end{array}$ & $\begin{array}{l}\text { Luzon-14 provinces } \\
\text { and } 7 \text { cities in the } \\
\text { National Capital } \\
\text { Region }\end{array}$ & USAID & $\begin{array}{l}\text { 2013-2018 } \\
\text { (completed) }\end{array}$ \\
\hline 12 & $\begin{array}{l}\text { Integrated Maternal, Neonatal, Child } \\
\text { Health, and Nutrition/Family } \\
\text { Planning Regional Project in } \\
\text { Mindanao (MindanaoHealth) }\end{array}$ & $\begin{array}{l}\text { RTI International and } \\
\text { Jhpiego }\end{array}$ & $\begin{array}{l}\text { Mindanao-19 } \\
\text { provinces and } 2 \\
\text { cities }\end{array}$ & USAID & $\begin{array}{l}\text { 2013-2018 } \\
\text { (completed) }\end{array}$ \\
\hline 13 & $\begin{array}{l}\text { Integrated Maternal, Neonatal, } \\
\text { Child Health, and Nutrition/Family } \\
\text { Planning Regional Project in Visayas } \\
\text { (VisayasHealth) }\end{array}$ & EngenderHealth & Visayas & USAID & $\begin{array}{l}\text { 2013-2018 } \\
\text { (completed) }\end{array}$ \\
\hline 14 & $\begin{array}{l}\text { Alternative Learning System (ALS) } \\
\text { Program }\end{array}$ & $\begin{array}{l}\text { Philippines Department } \\
\text { of Education (DoEd) }\end{array}$ & Nationwide & $\begin{array}{l}\text { Philippines } \\
\text { Government with } \\
\text { some support from } \\
\text { UNICEF }\end{array}$ & 2005-present \\
\hline 15 & $\begin{array}{l}\text { Street Education and Protection } \\
\text { Program (STEP) }\end{array}$ & $\begin{array}{l}\text { ChildHope Asia } \\
\text { Philippines }\end{array}$ & $\begin{array}{l}15 \text { areas in } 6 \text { cities } \\
\text { of Metro Manila }\end{array}$ & $\begin{array}{l}\text { N/A, but mentioned } \\
\text { UNICEF in their } \\
\text { program }\end{array}$ & 1995-present \\
\hline
\end{tabular}




\section{BOX 2 PROGRAMS TARGETING ADOLESCENTS AGED 15 TO 19 AS KEY BENEFICIARIES}

ALS: Alternative education

U4U: Teen pregnancy and STIS

AHDP: Delay of sexual debut, use of modern contraceptives, teen pregnancy, and STIS

Youth Program of RoH: Use of modern contraceptives and STIS

Adolescent and Youth Program of UNFPA: General $\mathrm{RH}$

VisayasHealth: maternal and newborn health, use of modern contraceptives, and care-seeking in first trimester

youth, and women of reproductive age in communities where the programs operated and in society as a whole, with OSY included as potential beneficiaries. One program (Youth Program of Roots of Health $(\mathrm{RoH})$ ) had no coverage of OSY at all, as it was a school-based program.

Six programs (U4U, ALS, AHDP, Youth Program of $\mathrm{RoH}$, Adolescent and Youth Program of UNFPA, and VisayasHealth) clearly state that adolescents aged 15 to 19 years old are a key target group. On the other hand, nine programs did not have set age criteria for their target group, and thus could include 15- to 19-year-olds, though they were not explicitly stated as a target beneficiary. Only one of the four OSY programs (ALS) specifically targeted OSY aged 15 to 19 years old.

The review reveals that OSY and adolescents aged 15 to 19 years old have been specifically targeted to some extent in the programs reviewed. However, OSY as a group seem to receive relatively less program attention than do adolescents aged 15 to 19 (four programs vs. six programs). Some programs did not explicitly mention OSY or adolescents aged 15 to 19 in their program documents, but it is possible that these programs benefit those groups as well, since the programs targeted the general population of young people at the project sites or in society.

\section{Inclusion of the four priority FP and RH behaviors}

The four OSY programs identified did not focus specifically on any of the four priority FP and RH behaviors noted above. Instead, the OSY programs focused on the provision of education outside the formal education system and of information about other necessary skills for OSY to obtain employment and live independently in society.

In contrast to the four OSY-oriented programs, five out of the six programs that targeted adolescents aged 15 to 19 focused on different aspects of AYRH. However, only three of these programs focused on one or more of the four priority FP and $\mathrm{RH}$ behaviors. The other two programs aimed to improve AYRH in general.

\section{Delay of sexual debut}

This priority behavior was explicitly mentioned by only one program (Youth Program of RoH), while prevention of teen pregnancy and transmission of HIV/sexually transmitted infections (STIS) among adolescents were targeted by six programs included in this review (U4U, AHDP, Youth Program, LuzonHealth, MindanaoHealth, and VisayasHealth).

\section{Use of modern contraceptives}

This priority behavior received more program attention than the other three priority behaviors. Eight programs (AHDP, ACER, U4U, Healthy Pregnancy Program, Primary Health Care Services and Counseling for Women by Likhaan, LuzonHealth, MindanaoHealth, and VisayasHealth) aimed to improve adolescents' or young women's access to FP services.

\section{Care-seeking in the first trimester}

This priority behavior was not specifically noted in these terms in project documents. However, six projects aimed to improve maternal health outcomes, for example, by having four antenatal care visits which may have included mothers aged 15 to 19 .

\section{Birth spacing of three to five years to prevent immediate repeat pregnancy}

Although five programs focused on FP, it was not clear from the program documents whether they aimed to promote FP for the specific purpose of birth spacing of three to five years. Only one program (Healthy Pregnancy 
Program) mentioned the words "birth spacing" in their program objective.

This analysis shows that there are programmatic gaps among reviewed programs. Programs that targeted OSY tended to focus on education and life-skill aspects rather than AYRH or FP. Although OSY is a subpopulation of adolescents who are the main beneficiary groups of at least six of the reviewed AYRH programs working, failure to target OSY specifically as a key beneficiary could result in their exclusion or hindrance in coverage, as they are typically difficult to reach with programming.

The analysis also found that the four priority FP and $\mathrm{RH}$ behaviors do not receive equal program attention. The use of modern contraceptives appears most prominently in the program documents. Reviewed programs are observed to have promoted this priority behavior, but without explicit mention of birth spacing of three to five years to prevent immediate repeat pregnancy. To achieve the latter, targeted/specific messages and strategies beyond only those related to providing access to modern contraceptives are needed. Similarly, although delaying sexual debut-a focus of several of the reviewed programs-could be one of the strategies to prevent teen pregnancy, program documentation did not draw clear connections between these two outcomes. On the contrary, as desirable maternal health outcomes begin with proper care during the first trimester of pregnancy, despite a lack of explicit mention of the priority behavior in project documentation, a number of reviewed programs that focused on maternal health promoted care-seeking in the first trimester through antenatal care visits. This was confirmed during consultations with stakeholders during the B-R's scoping visit to Manila at the inception of the study.

\section{SBC approaches}

The reviewed programs adopted a range of SBC approaches, including health education and promotion, information sharing, demand generation for health services and products, capacity building of service providers, health system strengthening, resource mobilization, and advocacy for policy changes, to achieve their objectives. The SBC approaches were implemented at three levels: individual, community, and policy/system. Approximately half of the reviewed programs were implemented at all three levels.

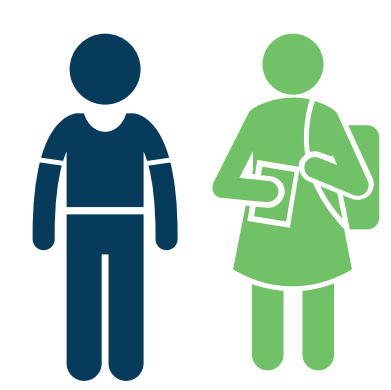

\section{Individual level}

At the individual level, several approaches were adopted: interpersonal communication; targeting capacity/knowledge building; and delivering key messages to individuals. The reviewed programs commonly utilized formal skill development training/education sessions, facility-based counseling with health providers, peer education, and media and information communication technology (ICT) as their key SBC approaches. These are described in more detail below. The programs either worked directly with end beneficiaries (i.e., youth) or with those who would work with youth. Engagement with the latter group was done with the expectation that interaction with them will lead to desired behavior change among youth.

\section{Formal skill development training/education sessions:}

This approach was adopted by a majority of the reviewed programs. Program activities implemented using this approach aimed to improve the life skills of youth and/or FP and RH knowledge of youth and health service providers, with the expectation that the latter would improve the quality of interaction between health providers and youth clients. For example, ADAPP and MYDev provided training on leadership and livelihood skills for youth, while STEP delivered an alternative education program for street children. AHDP trained health and non-health personnel to provide adolescent-friendly health services. Similarly, Youth Program trained education personnel to provide comprehensive sexuality education. The Healthy Pregnancy Program trained local barangay and municipal health nurses and midwives who are frontline health workers and women leaders from each community to become community health advocates (CHAs).

Peer education: Apart from institutionalized education sessions, knowledge/skill building took place in a more unstructured but interactive manner through peer education. A common title for peer educators among the reviewed programs was "advocate." AHDP trained adolescents to become peer educators using the Healthy Young Ones program. Similarly, STEP recruited and trained select street children to become Junior Child Rights Advocates 
and Junior Health Workers to implement education activities for peers and other street children.

Media and ICT: This approach was used to reach individuals as well as the wider community for different purposes but was not observed to be widely used among reviewed programs. Only three programs employed this approach extensively: ACER, U4U and MyDev. ACER utilized a mix of social media (e.g., Twitter) and applications (e.g., Grindr) and online promotion to reach populations at high risk for HIV. U4U utilized online portals and mobile Interactive Voice Response platforms to deliver information to adolescents on AYRH issues, including preventing teen pregnancy and STIs. MYDev trained youth on employability skills and then used the Work Ready Now (WRN) application, a digital assessment tool, to assess students' readiness for employment.

\section{Facility-based counseling with health providers:}

This channel was adopted by only a few programs and employed in integrated SBC programs where counseling for one service was used to promote the use of another health service; however. For example, LuzonHealth used individual counseling sessions to deliver age-specific messages to generate demand for services from men, women, and adolescents. The project delivered FP messages for mothers who visited a health facility for their child's immunization.

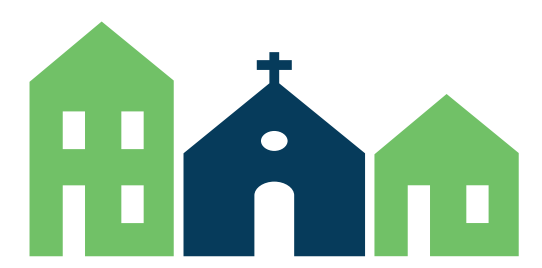

\section{Community level}

The main purposes of program activities implemented at the community level were generally health-related information sharing, demand generation, distribution of health services and products, and resource mobilization. Popular approaches include community outreach, community engagement and mobilization, social movement, and media and ICT. These are described in more detail below.

Community outreach: This was the most popular SBC strategy employed at the community level. The purpose of activities implemented under this approach was to disseminate health-related information, distribute health services/products to hard-to-reach populations, and/or generate community-wide demand for health services. For example, AHDP provided sexual and reproductive health (SRH) information to adolescents, parents, and others at health facilities and during the program staff's visits to communities. The program also established adolescent-friendly health service centers, which were equipped with logistics and supplies necessary to provide essential adolescent health services. Youth Advocates in the Youth Program also distributed condoms in their local communities and invited their friends, peers, classmates, and colleagues to visit the program's health clinics for counseling and services. Under the Healthy Pregnancy Program, CHAs ensured that all pregnant women received regular prenatal check-ups during community clinical services. The check-ups included free prenatal vitamins and up-todate laboratory examinations with project-partnered local government centers. CHAs also accompanied women to hospitals and/or assisted with birth deliveries. ACER provided on-site information sharing and HIV testing as well as distribution of condoms and lube at cruising sites, high-density localities, bus stops, other similar modalities, and hospitality service establishments such as beauty parlors and salons, gay saunas and bath houses, and spas.

Community engagement and mobilization: This was the second most popular community level approach. Community members could be engaged at various stages of the program for different purposes. ALS conducted community-mapping exercises to identify and enroll OSY in their alternative education program. U4U used their "Teen Trail" program at schools and in communities to impart health information to youth and to mobilize resources from local sponsors. These programs were managed by teens themselves, and the events included interactive exhibits, fun workshops, songs and dances, distribution of calling cards, and postcards. STEP recruited and trained youth to become Junior Child Rights Advocates and Junior Health Workers. These youth became role models for other youth in the community and supported the program's peer education activities. The Healthy Pregnancy Program recruited strong female community leaders to serve as CHAs whose job was to ensure that all pregnant clients receive regular prenatal check-ups during community clinical services and also to accompany women to hospitals and/or to assist with birth deliveries. MYDev convened local governments and national government agencies, academia, and the private sector to conduct local market analyses, provide guidance on skills training courses to local training service providers, and link OSY with employment.

Social movement and empowerment: This approach, utilized by only one program at the community level, aimed to effect social change and empower target groups 
to communicate their needs more effectively. Community Organizing and Education Program established PiLaKK, a federation of 20 community-based organizations of young people with more than 4,000 members, adopted this approach to give communities a stronger voice and opportunities to pool resources and learn from each other. PiLaKK members were active in initiatives such as the "Reproductive Health Sentinels," where they were trained on how to look for and identify obstetric and other medical emergencies in the community and provide appropriate assistance.

Media and ICT: In this approach, media channels were used on a larger scale to communicate with and reach wider communities. Only two reviewed programs adopted this approach: U4U used online portals such as YouTube and interactive voice response systems, together with other site-based approaches, to impart RH knowledge to youth; ACER used social media, Tinder, Grindr, and similar dating apps as well as online media promotional campaigns to impart HIV-related health information and promote HIV testing among at-risk populations.

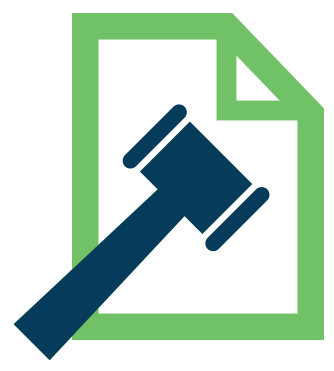

\section{Policy/system level}

At the policy/system level, the reviewed programs adopted three SBC strategies-namely advocacy, technical assistance, and network formation-to influence policy changes, empower young people and women, and strengthen the health system. Approximately half of the reviewed programs worked at this level.

Advocacy: The reviewed programs used various activities to appeal to the local or national government for the purpose of changing or adopting any health-related law. For example, PiLaKK advocated for universal healthcare and $\mathrm{RH}$. This federation helped women and youth from impoverished communities have a voice in debates and take part in activities that could have critical effects on the quality of their lives. In addition, a joint statement issued by Likhaan, the University of the Philippines Institute, and the U.S.-based Guttmacher Institute about Filipino women at risk for unintended pregnancy was used to support

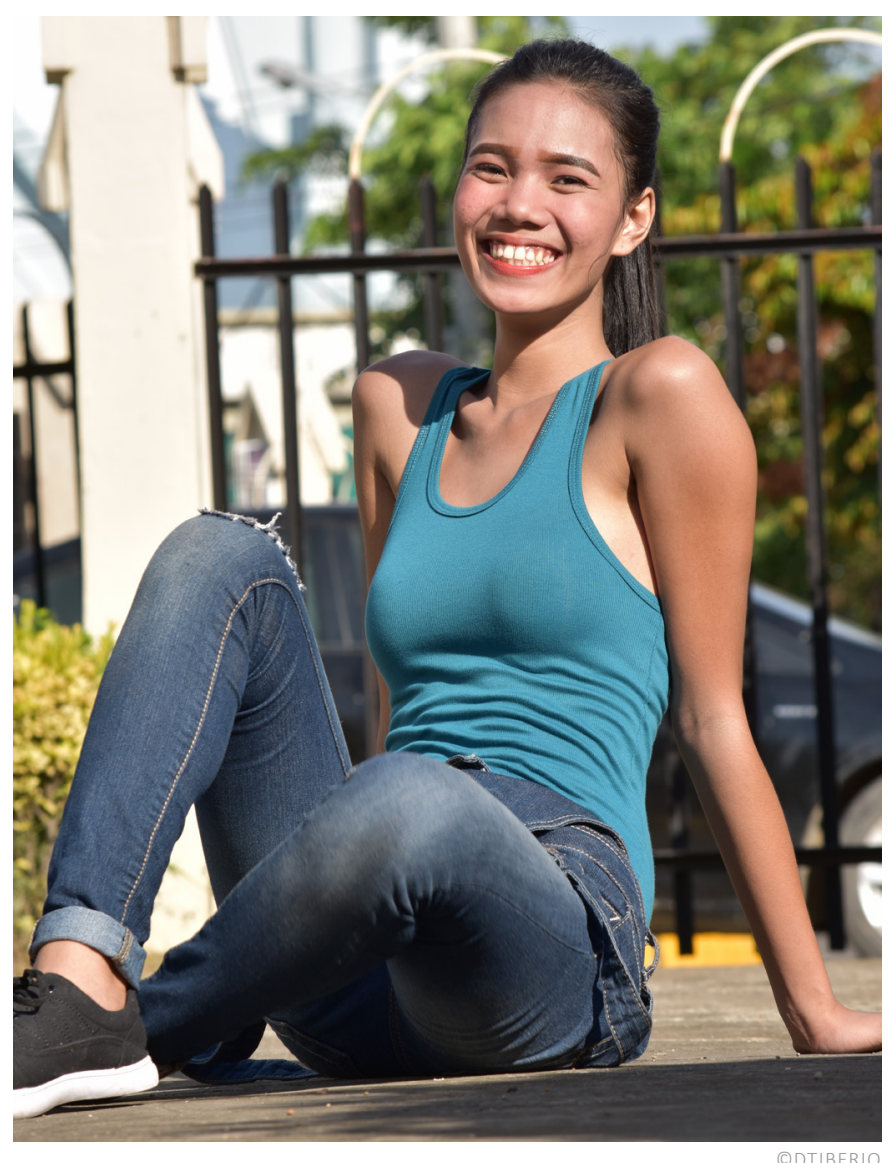

the potential passage of the RH bill. Another example is that of the Adolescent and Youth Program implemented by UNFPA and national agencies. The program advocated for Mindanao local government units to integrate AYRH in their development plans. VisayasHealth also worked to remove local policy and health system barriers to providing improved services for adolescents and youth. The program facilitated issuance of supportive local policies and improved training as well as the development of a supervision system to facilitate higher-quality services for adolescents and youth.

Technical assistance: Programs implementing this approach provided technical support to the local or national government to improve their quality of work or the overall health system. For example, MindanaoHealth supports the Department of Health-led scale-up of high-impact services and client-centered information to improve child health and nutrition, reduce maternal and infant deaths, and decrease unmet need for FP services, especially among the lowest-wealth quintiles and in conflict-affected areas in Mindanao. The program also helps the Department of Health strengthen health systems, sustain health service improvement, and reach people living in rural areas. VisayasHealth and LuzonHealth both 
provided technical assistance for training across the continuum of care, which aims to improve the quantity and quality of FP and maternal, neo-natal, and child health and nutrition service providers.

Network/group formation: Group advocacy was sometimes utilized to create a collective voice; in other instances, it was employed to support the health system or program implementation. For example, AHDP set up the Service Delivery Network for Adolescent Health, developed a referral directory, forged partnerships with referral facilities, referred adolescents to appropriate services or referral facilities, and developed a referral tracking mechanism. MYDev established OSY development alliances in eight cities and municipalities for resource mobilization and other support activities for the project.

\section{Program evaluation}

This scoping review revealed a number of evidence gaps among the past and present programs that were reviewed. An important evidence gap identified was that rigorous evaluation of program implementation was limited. While some programs had end-of-project evaluations, often such reports were not made public and therefore were not easily accessible. UNFPA and UNICEF country program evaluations were usually conducted at the end of each program cycle but were not specific to individual programs. Most programs undertook internal ongoing assessments of the success of their program implementation, for example using pre- and post-training tests, but lacked true population-based rigorous evaluations utilizing counterfactuals. For example, U4U did not conduct a formal evaluation of their program but conducted a cross-sectional study using an online survey where they performed a statistical test of participants' assessment at the end of the Teen Trail program and explored the relationship between knowledge, attitudes, and intentions to have sex. In ALS, the Filipino Department of Education collects data on ALS enrollees and program operations every year as part of routine program monitoring and also conducts periodic snapshot surveys, the last of which was performed in 2017 with a randomly selected sample to assess program impacts. None of the programs reviewed included a program evaluation that included at least a quasi-experimental design with control groups, so the true impact of the reviewed programs is undetermined.

\section{CONCLUSION}

The results of this scoping review reveal several important conclusions about past and present SBC programs for adolescents and youth in the Philippines. Out of the 15 programs under review, only approximately one-third targeted OSY, and when they did, they tended to focus more on aspects of education and life skills rather than FP and $\mathrm{RH}$. A similar proportion of programs targeted adolescents aged 15 to 19 as their key beneficiaries, and nearly all among them focused on AYRH. Although a majority of the reviewed programs focused on $\mathrm{FP}$ and $\mathrm{RH}$ of adolescents or young women and men in general, available information suggested that the four priority FP and $\mathrm{RH}$ behaviors identified by our study received uneven programmatic attention. The use of modern contraceptives and care-seeking in the first trimester seemed to be the two most targeted behaviors, stated explicitly or addressed indirectly as part of the implementation. It could not be definitively inferred from the existing program documentation whether the remaining two behaviors, namely the delay of sexual debut and birth spacing of three to five years to prevent immediate repeat pregnancy, have also been focus areas among the reviewed programs, but supporting evidence exists that they may have been indirectly addressed.

The reviewed programs have adopted a wide variety of SBC approaches that work at different levels of the society (individual, community, and policy/system). There appeared to be no differentiation by age group in terms of communication approach, between programs targeting adolescents aged 15 to 19 and the general population of women and men of reproductive age. The most common forms of SBC strategies were training and peer education (at the individual level), community mobilization and outreach (at the community level), and advocacy and technical assistance (at the policy/system level). The use of media and ICT to influence SBC remains limited in the Philippines. Limited information is available about message framing and influencers for age-specific audiences in the reviewed programs, as communication materials are often not shared publicly. The effectiveness of the strategies and approaches to promote SBC among target groups of the reviewed programs remains unclear due to the lack of rigorous evaluation of interventions. 


\section{RECOMMENDATIONS}

Based on the findings of the scoping review, we offer the following recommendations for future programming and policy in the Philippines related to improving AYRH among OSY.

1. More programs should explicitly focus on OSY aged 15 to 19 . Only one program in the review explicitly focused on this particular target group.

2. To better address the behaviors of OSY, specific programs that target OSY and FP and RH behaviors are needed. OSY programs reviewed in this study focused predominantly on the alternative education and life skills of those who are not in school. As OSY remain outside of formal programs and structures, they remain at high risk of being overlooked for FP and RH programming without being explicitly targeted.

3. Programs should be more specific and explicit about the FP and RH behaviors they are targeting in their program objectives, design, and documentation. Some FP and RH priority behaviors of concern, such as delay of sexual debut or birth spacing of three to five years, were not explicitly highlighted in program documentation. It would be advantageous to be more specific and strategic about such targeting than to assume that these will be achieved under broader strategies such as improving the use of modern contraceptives or prevention of teen pregnancy. In other words, a strategy to prevent teen pregnancy does not necessarily lead to delay of sexual debut.

4. Programs should increasingly employ mass media and ICT as an SBC approach at all three levels (individual; community; and policy/system). Out of 15 reviewed programs, only three programs adopted this approach at the individual level, and only two programs adopted it at the community level. This was surprisingly low, particularly given the potential reach and potential of mass media and ICT approaches and their popularity with the target group of OSY.

5. Programs should better document their interventions, approaches, and methods and make them available to the public for collective learning and coordination of approaches and interventions from implementers in the field. The level of documentation of programs reviewed was limited, and the study team had to depend on in-person interviews and connections with program implementers to identify some strategies that were not documented in publicly available program documentation.

6. Programs should adopt rigorous evaluation designs to generate strong evidence of what works or does not work to achieve outcomes in FP and RH for young people utilizing targeted SBC. None of the reviewed programs adopted a rigorous enough design (e.g., at least a design involving a comparison or control group) to determine the impact of interventions. More rigorous evaluations will enable scale-up of interventions shown to be effective and changes in program design and strategy if interventions are not showing impact.

\section{ANNEX 1}

\section{LIST OF PROGRAMS AND ORGANIZATIONS CONSULTED FOR THE SCOPING REVIEW IN SEPTEMBER 2018}

No. Organization

1 CLAimHealth (USAID), Panagora Group

2 UNICEF

3 U.S. Agency for International Development (USAID)/ Office of Health

$4 \quad$ Family Planning Organization of the Philippines

$5 \quad$ Likhaan Centre for Women's Health

$6 \quad$ Center for Health Solutions and Innovations Philippines (CHSI)

$7 \quad$ UNFPA

8 Philippine NGO Council on Population Health and Welfare

9 Save the Children Philippines/USAID HIV Project

10 Roots of Health

11 Luzon Health

12 Philippines Department of Health/Disease Prevention and Control Bureau 


\section{Contributors}

Ashish Bajracharya

Molyaneth Heng

Paul Hewett

Laura Reichenbach

\section{Acknowledgments}

We are grateful to the stakeholders from various programs, governmental and non-governmental organizations in Manila who provided their valuable time to meet and speak with us during the scoping visit for this study, to improve our understanding of the AYRH programming landscape in the Philippines. Special thanks also goes to the USAID/Philippines for their guidance over the course of the study.

\section{Suggested citation:}

Breakthrough RESEARCH. 2020. "Social and behavior change programming landscape for out-of-school adolescent and youth reproductive health programs in the Philippines: a scoping review," Programmatic Research Brief. Washington, DC: Population Council.

C2020 The Population Council. All rights reserved.

\section{Email}

\section{BreakthroughResearch@popcouncil.org}

\section{Breakthrough RESEARCH | Population Council}

4301 Connecticut Ave., NW, Suite 280 | Washington, DC 20008

+12022379400 | breakthroughactionandresearch.org

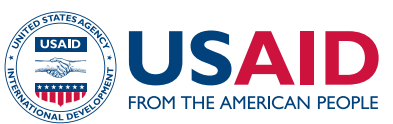

Breakthrough RESEARCH is made possible by the generous support of the American people through the United States Agency for International Development (USAID) under the terms of cooperative agreement no. AIDOAA-A-17-00018. The contents of this document are the sole responsibility of Breakthrough RESEARCH and Population Council and do not necessarily reflect the views of USAID or the United States Government.

\section{POPULATION COUNCIL}

Ideas. Evidence. Impact.

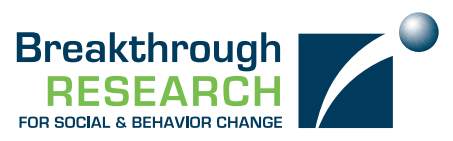

Breakthrough RESEARCH catalyzes social and behavior change (SBC) by conducting state-ofthe-art research and evaluation and promoting evidence-based solutions to improve health and development programs around the world. Breakthrough RESEARCH is a consortium led by the Population Council in partnership with Avenir Health, ideas42, Institute for Reproductive Health at Georgetown University, Population Reference Bureau, and Tulane University. 